\title{
The Best Science is Inclusive of African Americans
}

\author{
Karen Patricia Williams
}

Published online: 14 September 2021

(C) The New York Academy of Medicine 2021

According to the 2020 Census, 46.9 million people are African Americans/Black. There is a need to ensure that biomedical research reflects the prevalence of disease in African Americans relative to the population demographics. This will require reflective forethought that is visible throughout the research proposal from the conceptual framework to recruitment and retention plans that include sample size calculations that account for over sampling to ensure enough African Americans are in the sample for meaningful analysis. It is important for the scientific community to understand African Americans are not a monolithic people, and there is a need for population specific studies. Even the way we apply and define "the best science" needs to change. If African Americans are not included in the proposed science when there is clear technical merit, be it instrumentation and pharmaceutical development or intervention implementation, the question that has to be asked is, is this the best science that is being proposed?

The explanations from researchers that say "they can't recruit African Americans" or "in our State we have very few people of color" or "it is so hard" are not acceptable. These may indeed be the reality for some scientists but that does not make it acceptable

K. P. Williams $(\bowtie)$

Martha S. Pitzer Center for Women, Children and Youth, College of Nursing, The Ohio State University, Columbus, $\mathrm{OH}$, USA

e-mail: williams.5963@osu.edu according to the National Institutes of Health Policy and Guidelines on The Inclusion of Women and Minorities as Subjects in Clinical Research, based on the federal law 42 USC 298a-2 [1]. The three exceptions, which are not mentioned above, are: [The law] "shall not apply to a project of clinical research if the inclusion, as subjects in the project, of women and members of minority groups, respectively-(1) is inappropriate with respect to the health of the subjects; (2) is inappropriate with respect to the purpose of the research; or (3) is inappropriate under such other circumstances as the Director of NIH may designate." Applying this law is a challenge to some who submit research and some who review research. Nonetheless, the principle of inclusion has to be grounded in the question is this the best science from the perspective of the researcher and reviewer, if it does not include African Americans. If not, does it meet the three-exception standard?

The papers included in this special issue demonstrate there is not one way to recruit and retain African Americans and that it takes effort. Some fall short of the intended recruitment goal. This happens when recruiting White populations as well, yet researchers continue to recruit them. Recruitment takes work.

Using a variety of strategies may be necessary. Scientists might want to begin by taking a critical examination at who is on the research team and at what point during the research continuum is the recruitment and retention plan developed. The time to build the potential relationships with people of interest and 
stakeholders is in advance of needing them. Again, this takes time and is not always easy. A popular default strategy is to set up an advisory board, which can be helpful. However, if their input is solicited after the research approach has been designed and they are contacted just in time to gather letters of support, it becomes a facade and the population of interest and stakeholders recognize it. Some who head community-based organizations will be offended and refuse to participate.

In preparing to work with a group of new people, it is important to engage in what I have coined as research readiness [2]. Research readiness is drawing from the science of literacy that posits before one can learn to read the learner must have certain fundamentals in place, like knowledge application. For example, learning and understanding African Americans are not a monolithic population, that our social networks exist beyond our faith-based organizations and that civic and fraternal organizations are valued beyond the bond of one's college experiences. This appears to be lost on the majority of the scientific community who engage in population-based research, underscoring the need for population specific studies.

Even though I am African American with an innate and intimate understanding of my community and share some of the same religious beliefs, I have to keep in mind that in my role as a researcher I am an outsider. I am a person desiring to enter into the community as a professional. I understand the gatekeepers will vet me. It is my responsibility to help my team to understand this is a normal process. It is important to help the university community to understand that we include stipends, snacks, space, transportation, etc. in the grant in addition to administrative overhead even if it means trimming investigator effort. Research readiness includes being accountable not just to the scientific community but to the African American community. To ethically disseminate the findings to the stakeholders and other community leaders, from the outset, before submitting the proposal, while still in the vetting stage, it is important to make a commitment to the African American community that the team is not going to do business as usual. That it is not going to be research drive-byes, collect the data from the people and move on to the next study. Nor are they going to engage in data mining, collect all the data they can regardless of its relevance to the study. Instead, the research team will publically report the findings at appropriate times during the research process and always at the end of the study. This means inviting the local Black physician and nurse associations to various activities hosted by our institutions with the intention of getting to know them, and without asking them for anything. Share prior research findings that have clinical implications and practical use for their practices. Ask them what the institution can do for them and their practices. This is part of building the relationship, building trust so that people do not feel used but instead are vested in the work and are willing to partner to promote it.

The COVID pandemic has taught us our health is intricately connected; we are as healthy as the person next to us. If African Americans are only minimally included or even excluded from research, we will not achieve health equity.

\section{References}

1. https://grants.nih.gov/policy/inclusion/women-and-minor ities/guidelines.htm. Accessed August 18, 2021.

2. Williams KP. Research readiness: preparing the team, institution and community for research. Underreview.

Publisher's Note Springer Nature remains neutral with regard to jurisdictional claims in published maps and institutional affiliations. 